\title{
Essay
}

\section{Stagger Lee \\ How Violent Nostalgia Created an American Folk Song Standard}

\author{
Duncan Williams \\ University of York
}

\begin{abstract}
Tradition ist die Weitergabe des Feuers und nicht die Anbetung der Asche. $\sim$ Attr. Gustav Mahler (1860-1911, German composer)
\end{abstract}

Tradition is tending the flame, not worshipping the ashes (Translation by author)

\section{Tending the Flame}

There is a long tradition of storytelling in folksong. Before methods for transcribing and later for recording definitive versions existed, the oral tradition was used to pass on tales and deeds. And, as anyone familiar with 'Chinese whispers' will know, this process is not always accurate. Even when transcription methods had become available, the accuracy of the record can be questioned, as is the case in Sabine Bearing-Gould (1834-1924), an 18th century Anglican reverend, perhaps most famous for his earnest documentation of werewolves (Baring-Gould 1973), as well as many collections of English folk song, which were often unsurprisingly edited from the pious perspective of a religious man of the time, likely due to the collectors profession. Often, such songs are cautionary or moral tales, and thus the process of collecting and editing can change an oral history dramatically.

This essay will consider how one such instance, the song Stagger Lee, reflects changing attitudes of the audience and the narrator towards violence and masculinity in its portrayal of an initially real-world, and later supernatural, violent protagonist. How, and why this paean to violence, with its fetishistic vision of extreme masculinity, has become something of a standard in the American folk canon. It considers both the retelling of Stagger Lee's tale in song, and subsequent appropriation by cinema in depictions of race, sex, and violence as admirable or heroic qualities. In particular, a kind of sexual violence which is perhaps at odds with stereotypical views on homosexuality amongst the African-American community, which spawned, and in some cases continues to celebrate, Stagger Lee as a mythoform, archetype, and antihero (Nelson 2005).

\section{Who was Lee Shelton?}

'Stagger' Lee Shelton (1865-1912) was an African-American carriage driver and sometime-pimp from Missouri (Eberhart 1996). He became immortalized as a folklore antihero after murdering a drinking partner, Billy Lyons, following a political argument gone bad in a St Louis saloon on Christmas day, 1895. Sentenced to 25 years in prison, Shelton died in Missouri State Penitentiary after violating his parole with a subsequent conviction for assault and robbery. 
'Stagolee came to personify the collective feeling of blacks at the bottom of society, and it was in this sense that Stagolee became a symbol of the black community' (Brown 2009).

\section{Stagger Lee in Song}

The song, Stack-a-Lee was first documented in 1897, becoming well known in African American communities along the lower Mississippi River over the following decade as Stagolee, Stagger Lee, Stack OLee and other variants (Price 1958). Two versions were published in the Fournal of American Folklore in 1911, with notable recordings entering the charts through the 1920s and beyond (Miller 2006). The range of alternative lyrics, whilst genuine records of the original perpetrator and his punishments exist, offers a unique opportunity to examine how violence and masculinity are exaggerated and revered: Lee's black Stetson hat is universal, but subsequent revisions describe the appearance of a caul across his face, implying a history of violence, and later superstition as he is said to have made a deal with the devil in order to take on the form of animals. Some readings of dehumanization in literature at the time suggest that this can indicate a reflection of slavery, especially pertinent in the southern states after emancipation in 1863 (Copeland 2013). However, descriptions of violence as animalistic were common in folklore of the time across Europe, for example, in the aforementioned Baring-Gould's interest in werewolves, wherein dehumanization becomes antonymous to behavior which the Baring-Gould would regard as morally accountable, in other words, his point of view was likely to consider violent deeds as non-Christian and analogously animalistic. In any case, the number and violence of Stagger Lee's crimes becomes exaggerated, almost exponentially over each new rendition, to the point of a tale of multiple murders and male rape in the 1995 version by Nick Cave and The Bad Seeds. Stagger Lee embodies the archetype of a violent and dangerous antihero as his story is retold, and perhaps a symbol of racial conflict in the United States.

Now Stackerlee, he told Billy Lyon,

'Billy, I'm sure gon' take your life.

You have win my money, jack, and I found a foul dice.'

Now Billy Lyon, he told Stackerlee,

He said, 'Stack, please don't take my life.

I have two little child'en and my poor little weakly wife.'

'Now, one of them is a boy, Stack,

And the other one is a girl.'

'But if you love your child'en, Billy Lyon, you will have to meet them in the other world.'

[...]

Now Stackerlee, he shot Billy Lyon

'Way down on that ballroom floor

It was early one mornin', just about fifteen to four

As sung by Foy Grant and filed in the library of congress by song collector Alan Lomax in 1934 .

A central point of the narrative, particularly in the Lomax transcription, is Billy, the main victim, begging for his life. Billy's begging forms the main hook of Bob Dylan's version, which portrays Stagger Lee as an outright 'bad' man. 
"You'll have to be gone before my man Billy Billy comes in,

Mr. Stagger Lee."

I'll stay here till Billy comes...

And furthermore I'll fuck Billy in his motherfucking ass.

[...]

Because I'm a bad motherfucker, don't you know?

And I'll crawl over fifty good pussies just to get one fat boy's asshole,

"Yeah, I'm Stagger Lee, and you better get down on your knees

And suck my dick because if you don't, you're gonna be dead, "

Said Stagger Lee

Billy dropped down and slobbered on his head

And Stag filled him full of lead

[scream]

As arr. and performed by Nick Cave and the Bad Seeds (Murder Ballads, 1994) ${ }^{50}$

Cave's Stagger Lee is presented in the form of a 'Toast', a pre-rap spoken word with its roots in Reggae and prison blues. Here, Lee states that he will sodomize Billy Billy when he arrives at the Bucket o' Blood inn, which also houses a bordello. This is loosely related to the true story in that Lee would have associated with prostitutes and did kill Billy Lyons in a gunfight in such a place (though allegedly in an argument over cards and a hat). However, here the similarities end. The wording is unambiguous, the threat becomes a brag, which becomes an action when Cave's antihero demands (and receives) oral sex at gunpoint from Billy Billy before killing him. Earlier versions depict Lee as an archetype of masculinity in line with commonly held stereotypes of African American culture, despite being an 'above-the-law' criminal. The same culture which revered and respected Lee has well-documented struggles with homosexuality (Lewis 2003; Black and Stevenson 1984; Constantine-Simms 2001). The unashamed nature of Cave's narrative implies a consciously contradictory revision to this archetype.

\section{Context Amongst Murder Ballads}

It would be unfair to characterize Stagger Lee as the only folk song which celebrates violence, or to imply that such songs only belong to the African American oral tradition - the truth could not be further from either statement. In fact, there is a rich history in the oral tradition of folk song which might initially seem grizzly or alien to first time listeners, in the murder ballad (Marshburn 1972). Perhaps it is no surprise that Nick Cave entitled the album containing his version of Stagger Lee, Murder Ballads (Cave et al. 2011). Such ballads were printed and sold on broadsheets as early as the mid 17th century in Europe, forming a notable portion of the repertoire available. Murder ballads often document true crimes, including in notable instances extreme crimes such as incesticide and fratricide, for example Edward, also known as Henry, What Put The Blood?, My Son David, and The Two Brothers, amongst other incarnations, is a murder ballad (Roud index 200). The details of the protagonist and his deeds are somewhat dependent on the geographic location, the moral compass of the collector, the number of generations of performer, and as is often the case in the oral tradition, the memory of

50 https://www.youtube.com/watch?v=Nbe5RERDh4k (accessed 1 January 2018) 
the singers themselves at the point of collection. As well as English, documented versions exist in, for example, Norwegian, Swedish, Danish, Icelandic, and Irish. The basic narrative is that the protagonist reluctantly confesses to his mother that he is responsible for the murder of his brother, her son. He is then exiled, by choice. Lizzie Wan, or Fair Lizzie (Child Ballad 51) changes the narrative slightly, such that Lizzie is pregnant with her brother's child, and the brother then murders her. As in Henry, over the course of the song the protagonist eventually confesses and exiles himself. Murder ballads are typically told from the point of view of a moral compass where the deeds are not glorified or vilified. In this context, Stagger Lee is more unusual. The difference is that the protagonist is portrayed both as a hero and subsequently as an archetype for his deeds. Perhaps, to establish the extreme nature of the character, we might ask ourselves: how many other leading protagonists are portrayed in song as heroic when having forced other men to commit a sex act? And how does this behavior not contradict typical or traditional views of masculinity (particularly in African American culture)? Ethnographic accounts of stereotypical (i.e., heterosexual) masculinity generally condemns such acts, particularly among males (Ernst et al. 1991). It seems clear that Stagger Lee conducts these acts in order to display power and dominance rather than for personal sexual gratification. We might consider at what point committing male rape constitutes a masculine act - perhaps in the balance between active and passive participant, as in many other cultures and subcultures, for example, ancient Greece - or that the act itself is perhaps less important than the subsequent formation of the archetype. The character must evolve to remain constantly interesting to new audiences, and retaining the power to shock is perhaps a part of Stagger Lee's mythos and popularity. If that is indeed the case, it is unsurprising that the metamorphosis of Stagger Lee has not been lost on the world of cinema.

\section{Appropriation in Film}

Stagger Lee seems to have an enduring popularity, partly due to the changing nature of his story, which ensures his tale remains up-to-date (it was most recently adapted to a musical in 2015). In the movie by the Memphis born Craig Brewer's Black Snake Moan, a 2006 film with sex and race at its core, Samuel L. Jackson stars as a Mississippi bluesman, Lazarus Redd, a religious man who imprisons the female lead, played by Christina Ricci, as part of his spiritual duty to help her overcome promiscuity. Critics considered scenes such as the naked Ricci chained to a radiator in Redd's kitchen as deliberately provocative, and again Stagger Lee appears as an allegory for shocking but normalized dominance. Redd performs Stagger Lee to the delight of a juke joint audience. The juxtaposition of a traditional, upbeat blues groove with Jackson's delivery, which lyrically owes a great deal to Nick Cave's 1995 treatment, is quite striking. Despite his character's religious back-story, both the audience and the narrator appear to revel in the misdeeds of Stagger Lee as Jackson's character describes them.

Few commercially successful film directors of the past two decades can match Quentin Tarantino's enduring ability to shock and court controversy, often with explorations of racial tension and sexualized violence, prompting some critics to describe his work as 'ultraviolent' (Bouzereau 2000). Indeed, even now, Tarantino's storytelling remains controversial amongst commentators with religious perspectives (Sheppard 2016). 
And I made him crawl through the snow on all fours over to it

Then I grabbed me a handful of that black hair at the back of his head

And I stuck my big black johnson right down his goddam throat

And it was full o' blood, so it was warm,

Oh you bet your sweet ass it was warm

And Chester Charles Smithers sucked on that warm black genghis for long as he could

[laughter from Warren]

You're starting to see pictures, aren't ya?

Your boy, black dude, genghis in his mouth

Him shaking, crying, me laughing

and him not understanding [...]

I never did give that boy a blanket.

Transcribed by the author from The Hateful Eight (Tarantino, 2015, The Weinstein Co.).

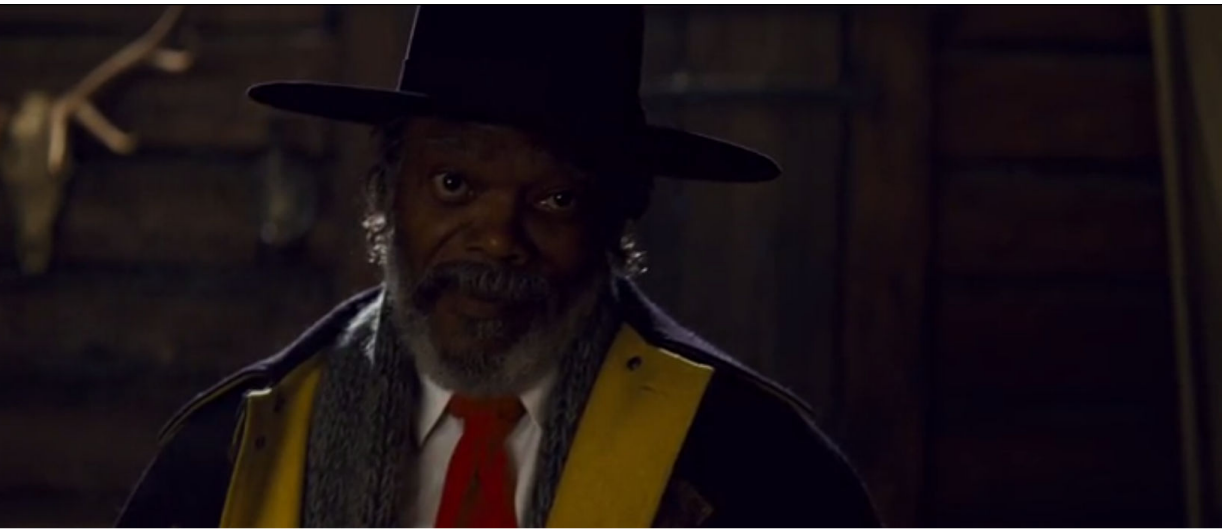

Fig. 2. Samuel L. Jackson as Major Warren in The Hateful Eight.

Another shooting ensues, with, as in Stagger Lee, the provocateur Major Warren surviving. The victim begging for his life in this scene is further reminiscent of Lomax and Dylan's interpretations of Stackolee. Jackson's comical delivery of Tarantino's script clearly suggests that the forced oral sex is not an act that Major Warren is ashamed of, on the contrary, his character appears extremely proud of himself. This becomes a kind of sublimation, as the distasteful is transformed into something enjoyable (Pfaller 2009). In this re-re-imagining of Stagger Lee, we see the villainous and extreme normalized through Tarantino and Jackson's presentation of Warren as an antihero. In the fourth 'Chapter', Major Warren pays an ironic price for his actions, when he is shot in the genitals by a hidden gunman, his proverbial masculinity revoked. Major Warren nevertheless goes on to survive despite his injuries, experience a redemption of sorts as he forges an unlikely working friendship with the remaining former confederate soldier which endures to the finale of the film. 


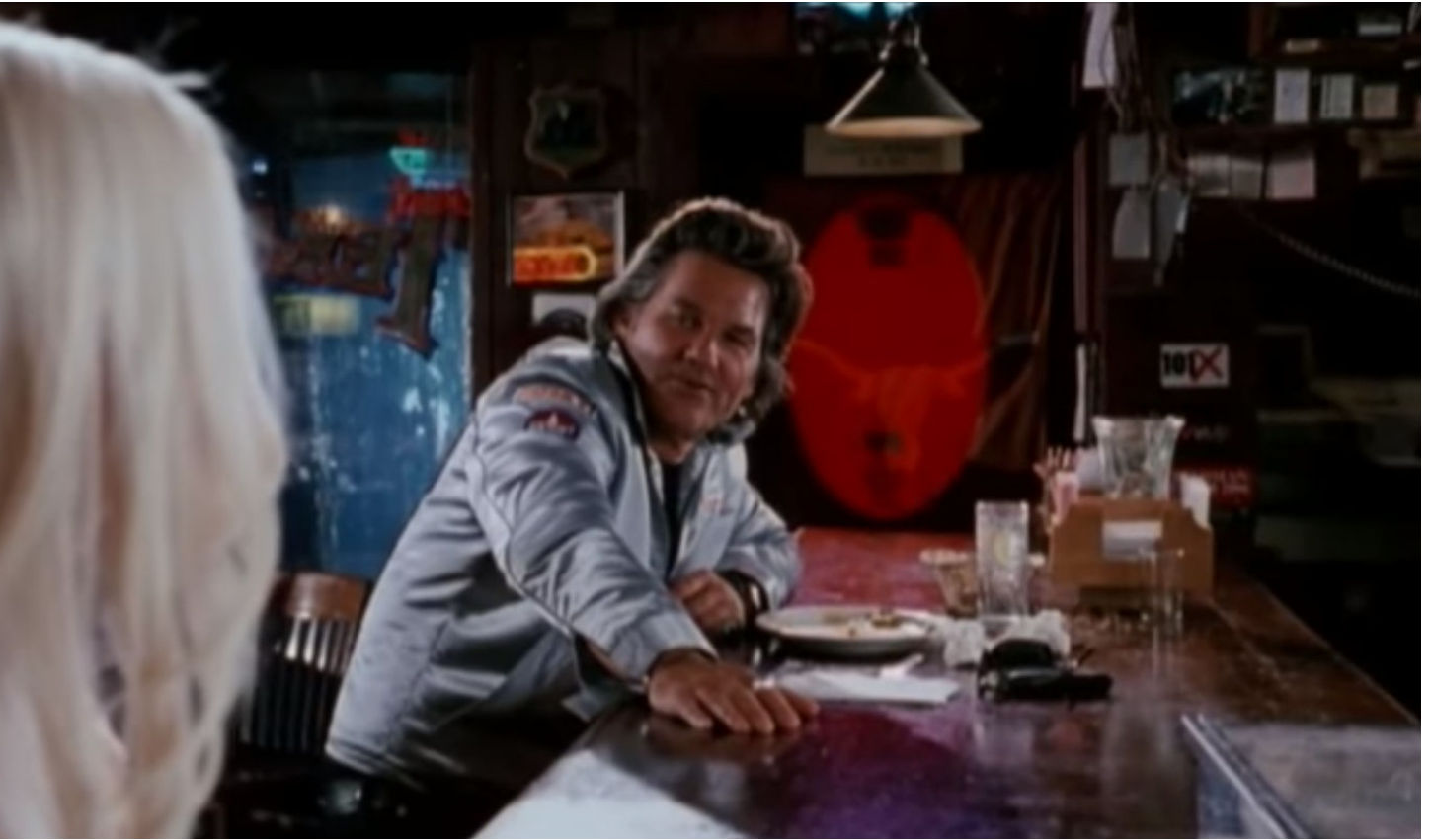

Fig. 3. Kurt Russell portraying Stuntman Mike in Tarantino's Death Proof. Note caul on the face, as the character of Stagger Lee is often described. A version of the song is playing in the background of this scene.

Death Proof shares a leading actor with The Hateful Eight in Kurt Russell, whose villainous character Stuntman Mike engages in a series of sexualized and sadistic murders (Anderson 2007). Stuntman Mike shares similarities with the fictionalized Stagger Lee: the protagonist of the tale (driving a 'death proof' muscle car), Mike has a caul across his face, and engages in a sexualised pursuit of his first victims, demanding a lap dance in the Texas Chili Parlor, a real-life dive bar in Austin, Texas. As in Stagger Lee, his victims have been drinking, and a version of Stagger Lee can be heard playing on the jukebox in the bar as Stuntman Mike engages in a dialogue with his victims in the first half of the film. Tarantino himself cameos as the barman in this sequence, and it seems unlikely that his choice of music is a coincidence. Tarantino is well-documented as a calculated soundtracker (Garner 2001), so it might be reasonable then to assume that these physical and personality traits are nods from the director to Stagger Lee as an archetype of sexualized violence, regardless of ethnicity.

\section{A Heritage of Violence: Concluding Remarks}

We might consider that nowadays there is a continuum between definitive article and living practice, and by being adaptable to such changes, songs like Stagger Lee can continue to enjoy new renditions and find new audiences. Changing attitudes to shock, sexualized violence, and masculinity in the past century can be seen in the adjustments made to Stagger Lee. Initially, a real-life murder ballad with a moral compass firmly suggesting that the protagonist was evil, and subsequently, towards a more fantastical anti-hero, especially in appropriations in recent film portrayals. The oral tradition, once a primary reference for historical storytelling, has been somewhat superseded by the technology of recording and distributing music: yet, the process of a recorded definitive 
article does not seem to have stopped Stagger Lee's evolution. We might infer a cultural mirror in the changes that occur in the narrative of his song, in our own views on violent storytelling and in the requirement to continually increase the shock factor in both songs and films. Does this tell us anything about the popularity of hyper masculine protagonists? Or is it simply in the capacity of a successful storyteller, like Tarantino, to manipulate masculinity in order to maximize impact? We know that his 'ultraviolent' movies are popular, and indeed that Stagger Lee has enjoyed an enduring popularity, for the purposes of this essay it is enough to state this popularity, rather than to consider why this heritage of violence should be popular. The why is beyond the scope of this essay, though perhaps as with most enduring songs, these are questions which are best left in the ear of the beholder in any case.

Anderson, Aaron G. 2007. "Stuntman Mike, Simulation, and Sadism in Death Proof." Quentin Tarantino and Philosophy, Chicago, Open Court, 13-20.

Baring-Gould, Sabine. 1973. "The Book of Were-Wolves: Being an Account of a Terrible Superstition. 1865." NY, NY: Causeway Books.

Barksdale, Aaron. 2015. "Quentin Tarantino On White Supremacy And Black Lives Matter." Huffington Post, December 9, 2015.

Black, Kathryn N, and Michael R Stevenson. 1984. "The Relationship of SelfReported Sex-Role Characteristics and Attitudes toward Homosexuality." Journal of Homosexuality 10 (1-2):83-93.

Bouzereau, Laurent. 2000. Ultraviolent Movies: From Sam Peckimpah to Quentin Tarantino. Citadel Press.

Brown, Cecil. 2009. Stagolee Shot Billy. Harvard University Press.

Cave, Nick, Blixa Bargeld, Martyn P. Gasey, Mick Harvey, P. J. Harvey, Kylie Minogue, Conway Savage, Jim Sclavunos, and Thomas Wydler. 2011. Murder Ballads. Mute.

Collin, Robbie. 2016. "Quentin Tarantino: 'The Confederate Flag Was the American Swastika." The Telegraph, January 2, 2016.

Constantine-Simms, Delroy. 2001. The Greatest Taboo: Homosexuality in Black Communities. Alyson Publications.

Copeland, M Shawn. 2013. "Blackness Past, Blackness Future - and Theology." South Atlantic Quarterly 112 (4):625-640.

Eberhart, George M. 1996. "Stack Lee: The Man, the Music, and the Myth." Popular Music E Society $20(1): 1-70$.

Ernst, Frederick A, Rupert A Francis, Harold Nevels, and Carol A Lemeh. 1991. "Condemnation of Homosexuality in the Black Community: A GenderSpecific Phenomenon?”' Archives of Sexual Behavior 20 (6):579-585.

Garner, Ken. 2001. "Would You Like to Hear Some Music? Music in-and-out-ofControl in the Films of Quentin Tarantino." Film Music: Critical Approaches, 188205.

Lewis, Gregory B. 2003. "Black-White Differences in Attitudes toward Homosexuality and Gay Rights." Public Opinion Quarterly 67 (1):59-78.

Marshburn, Joseph H. 1972. Murder \& Witchcraft in England, 1550-1640: As Recounted in Pamphlets, Ballads, Broadsides, \& Plays. University of Oklahoma Press. 
Miller, D. Quentin. 2006. "Playing a Mean Guitar: The Legacy of Staggerlee in Baldwin and Morrison." In Fames Baldwin and Toni Morrison: Comparative Critical and Theoretical Essays, 121-148. Springer. http://link.springer.com/chapter/ 10.1057/9780230601383 7 .

Nelson, Angela. 2005. "Rap Music and the Stagolee Mythoform." Americana: The Fournal of American Popular Culture, 4(1).

Pfaller, Robert. 2009. "Sublimation and 'Schweinerei' Theoretical Place and Cultural-Critical Function of a Psychoanalytic Concept." fEP: European Fournal of Psychonalysis, November 29: 11-48.

Price, Lloyd. 1958. Stagger Lee.

Sheppard, Christian. 2016. "The Hateful Eight. Film. Directed by Quentin Tarantino. The Weinstein Company, 2015." Religious Studies Review 42 (2):100100.

Duncan Williams is a Researcher in the Digital Creativity Labs at the University of York, UK. Prior to this he was a Research Fellow in Music with Artificial Intelligence at the Interdisciplinary Centre for Computer Music Research in Plymouth, UK, a postdoctoral Research MCR at Wolfson College, University of Oxford, and Information and Music Technology Officer for the Faculty of Music, University of Oxford. He holds a $\mathrm{PhD}$ from the University of Surrey, UK, and is a Fellow of the Higher Education Academy. He is an editorial board member of Musicae Scientae (Sage), Journal of Creative Music Systems (University of Huddersfield Press), and the audio section of the Encyclopedia of Computer Graphics and Games (Springer). A blog and publications list is periodically updated at http://www.duncanwilliams.info Contacting author: duncan.williams@york.ac.uk 